\title{
Ultra high performance fiber reinforced concrete for strengthening and protecting bridge deck slabs
}

\author{
M. Bastien-Masse \& E. Brühwiler \\ Ecole Polytechnique Federale de Lausanne, Lausanne, Vaud, Switzerland
}

\begin{abstract}
An original concept is presented for the durable rehabilitation of concrete bridge deck slabs. The main idea is to add a layer of Ultra-High Performance Fiber Reinforced Concrete (UHPFRC) with or without steel reinforcing bars over the concrete slab to create a composite section. The layer of UHPFRC strengthens the structural element for high traffic loads. Experimental studies on composite beams and slabs were carried out to study their behavior under various types of loading and identify the failure modes and the contribution of the UHPFRC layer to the resistance. Analytical models were then developed to calculate the resistance of composite beams. The concept has been validated by field applications demonstrating that the technology of UHPFRC is mature for cast in-situ.
\end{abstract}

\section{INTRODUCTION}

Concrete bridge deck slabs are exposed to severe environmental and mechanical loading. It is thus necessary to develop new technics to improve durability and increase load bearing capacity of these elements. The present study focuses on the case of bridge deck slabs with insufficient ultimate limit state capacity in bending and / or shear. To reinforce them, it is proposed to add a layer of Ultra High Performance Fiber Reinforced Concrete (UHPFRC) to the top of the slab, 25 to $75 \mathrm{~mm}$ in thickness, with or without small diameter steel reinforcement bars, thus creating a composite section (Fig. 1).

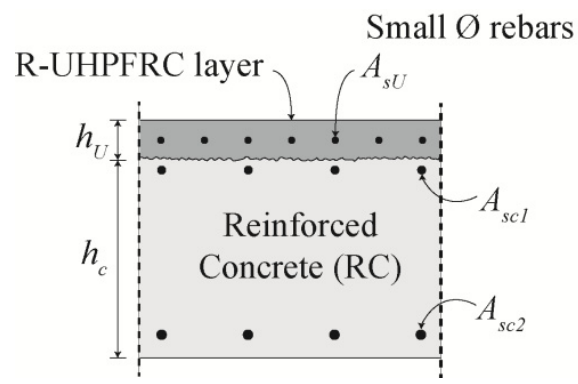

Figure 1. Typical composite section (Habel et al., 2007)

UHPFRC has excellent mechanical properties i.e., compressive strength higher than $150 \mathrm{MPa}$, tensile strength higher than $10 \mathrm{MPa}$ and with considerable tensile strain hardening and softening behavior (Denarié \& Brühwiler, 2011). The layer acts as an external reinforcement, increasing the bending and shear resistance of the element. An additional benefit of this improvement method is that UHPFRC has a very low permeability (Charron et al., 2007) and can serve as a waterproofing layer protecting the slab from the environmental influences such as water and chlorides.

The original conceptual idea (developed in 1999) has been investigated by means of extensive research aimed at characterizing UHPFRC as well as the structural behaviour of R-UHPFRC - RC composite structural members, combining material and structural engineering sciences. This paper presents the tensile behaviour of UHPFRC followed by the main results of a large experimental study on a series of composite beams and slabs. Using the test results, analytical models to predict the failure mode and resistance of composite beams were developed. To conclude a design example and a field application on a bridge in Switzerland are presented.

\section{UHPFRC IN TENSION}

As illustrated in Figure 2, the uniaxial tensile behaviour of UHPFRC is divided into three phases. First, the material is elastic up to initiation of microcracking of the matrix. The elastic limit strength $f_{U t e}$ has typical values of 7 to $11 \mathrm{MPa}$ for currently used UHPFRCs.

Second, it goes into a phase of strain hardening with multiple (non-visible) microcracking of the matrix and fiber activation. The material still behaves 
like a continuum. Strain hardening domain may reach strains of 2 to $5 \%$ where the tensile strength $f_{U t}$ is reached with typical values ranging from 9 to $15 \mathrm{MPa}$.
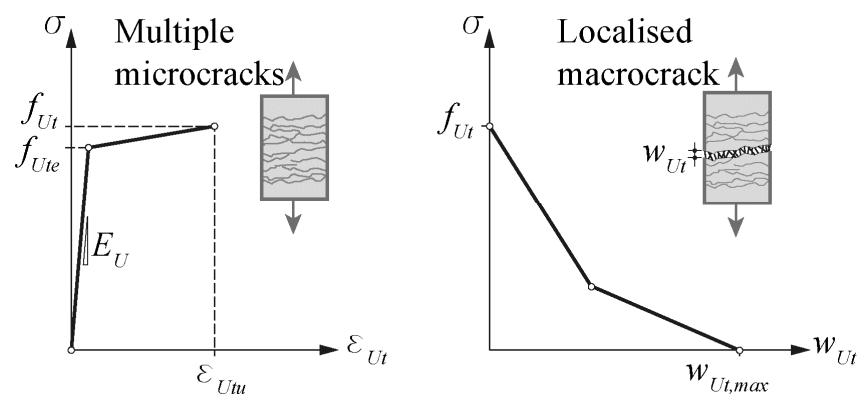

Figure 2. Tensile behavior of plain UHPFRC (Habel et al., 2007)

Third, upon the formation of a discrete macrocrack at ultimate resistance, the phase of strain softening begins and the behaviour of the material is described by a stress-crack opening law with maximum crack openings reaching about half of the fiber length, i.e., 5 to $8 \mathrm{~mm}$.

\section{EXPERIMENTAL INVESTIGATION ON COMPOSITE BEAMS AND SLABS}

The aim of the extensive experimental investigation is to understand the contribution of the UHPFRC layer to the behavior and resistance of composite beams and slabs under various types of loading. In the next paragraphs, the main conclusions of three series of tests are presented. In all cases, the UHPFRC layer was used as a tensile reinforcement.

\subsection{Bending tests}

Flexural tests were carried out on composite beams with a layer of $50 \mathrm{~mm}$ of reinforced UHPRC over a $250 \mathrm{~mm}$ high reinforced concrete section. The layer of UHPFRC increased the resistance up to $165 \%$ compared to a reference RC beam (Oesterlee, 2010).

At the serviceability limit state (SLS), the concrete is cracked but not the UHPFRC layer which controls the crack opening in the concrete and provides protection against water and chlorides (Fig. $3 a)$. Over the vertical macrocracks in the concrete, distributed microcracks develop in the UHPFRC layer. The flexural failure happens when a macrocrack localizes in the UHPFRC layer where the highest moment is applied. As seen in Figure 3b, no debonding is observed at the interface between the UHPFRC layer and the concrete prior to failure (Habel et al. 2007). It is thus supposed that the behavior of composite beams is monolithic when submitted to pure flexural moments.

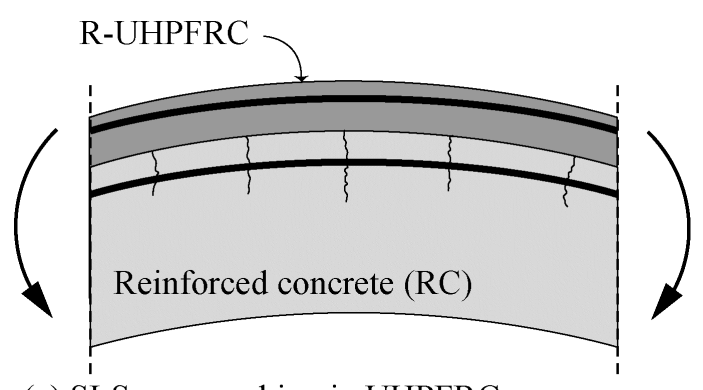

(a) SLS : no cracking in UHPFRC

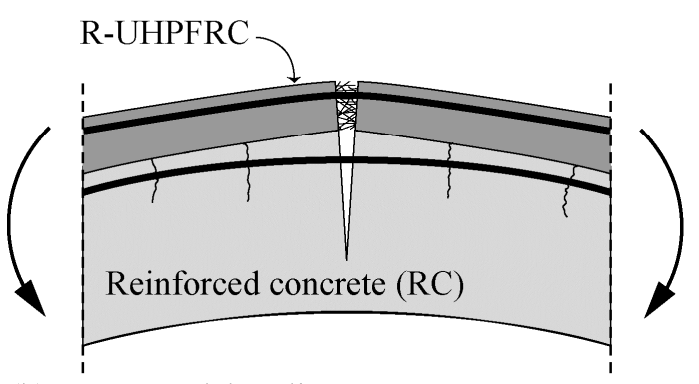

(b) ULS : no debonding

Figure 3. Behavior of composite section in bending

\subsection{Cantilever tests}

Subsequently to these flexural tests, composite beams placed in a cantilever test setup were submitted to combined bending and shear. These tests demonstrated that the layer of UHPFRC increases the resistance of the RC sections without modifying the rotation capacity when failing in shear (Noshiravani \& Brühwiler, 2013). In addition, the tests showed that for a RC section with insufficient shear capacity, an additional layer of UHPFRC, if designed accordingly, can also modify the failure mode from flexure-shear failure with little deformation to a ductile flexural failure.

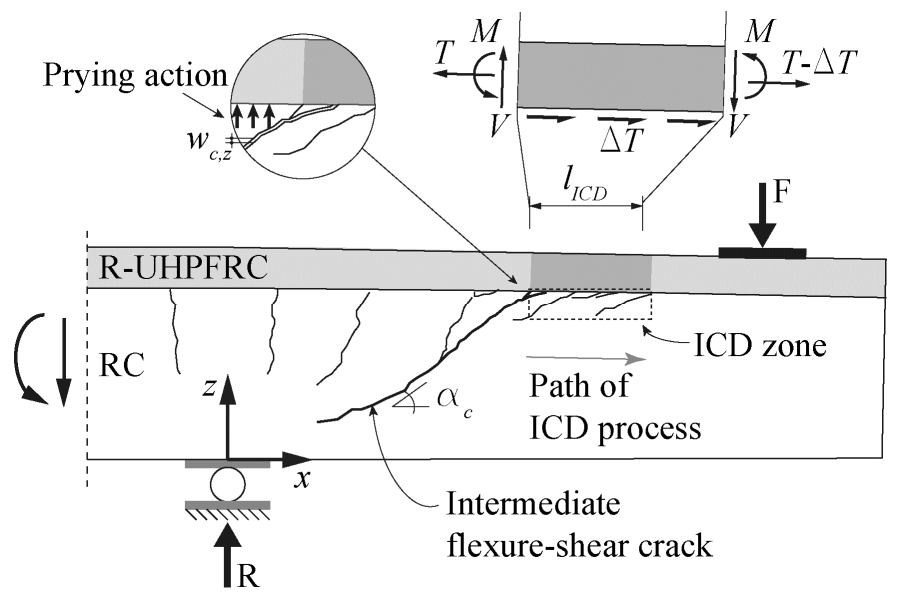

Figure 4. T Flexure-shear failure mode of composite beams (Noshiravani \& Brühwiler, 2013)

This test series allowed studying the flexure-shear failure mode of a composite beam and understanding how the UHPFRC layer contributes to the shear resistance of the member. A flexure-shear failure occurs when a flexural vertical crack in the RC section rotates towards the roller support and develops diag- 
onally. The widening of this inclined crack creates a prying action on the UHPFRC layer which induces a softening of the concrete below, as illustrated in Figure 4. This softening occurs between the mouth of the inclined crack and the point where the force acts and is known as the Intermediate-Crack induced Debonding (ICD) (Noshiravani \& Brühwiler, 2013). With this debonding, the section can no longer be considered as monolithic and the member stiffness decreases. Over the ICD zone, the R-UHPFRC layer resists to the prying action and is submitted to double curvature.

\subsection{Punching tests}

In order to study the behavior of larger specimens, a series of $3000 \times 3000 \times 260 \mathrm{~mm}$ composite slabs were fabricated and submitted to two-way shear. As seen in Figure 5, the layer of $50 \mathrm{~mm}$ of UHPFRC was easily casted over the concrete section.

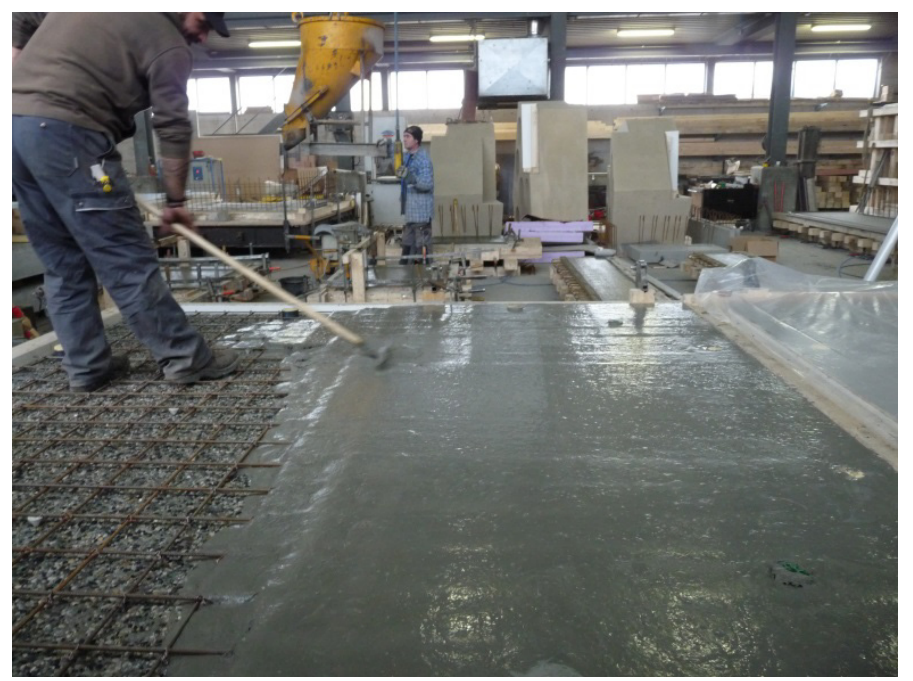

Figure 5. Placing of UHPFRC on large specimens

These slabs were then tested in a punching test setup, as illustrated in Figure 6a. The slab was placed on a column of $260 \times 260 \mathrm{~mm}$ and the force was applied in 8 points on the UHPFRC layer. Four composite slabs were tested. PBM1 to PBM3 all had a layer of $50 \mathrm{~mm}$ of UHPFRC. PBM2 and 3 had respectively standard and high performance reinforcement placed in the layer. The fourth slab, PBM4, had a plain layer of $25 \mathrm{~mm}$ of UHPFRC. The reference concrete slab PG19 was previously tested by Guidotti (2010).

The normalized force-rotation curves shown in Figure $6 \mathrm{~b}$ are obtained with Equation 1. This operation allows taking out the effect of the various concrete strengths and static heights (Muttoni, 2008).

$y=\frac{V}{b_{0} d \sqrt{f_{c}}}, x=\frac{\psi d}{d_{g 0}+d_{g}}$ (a)
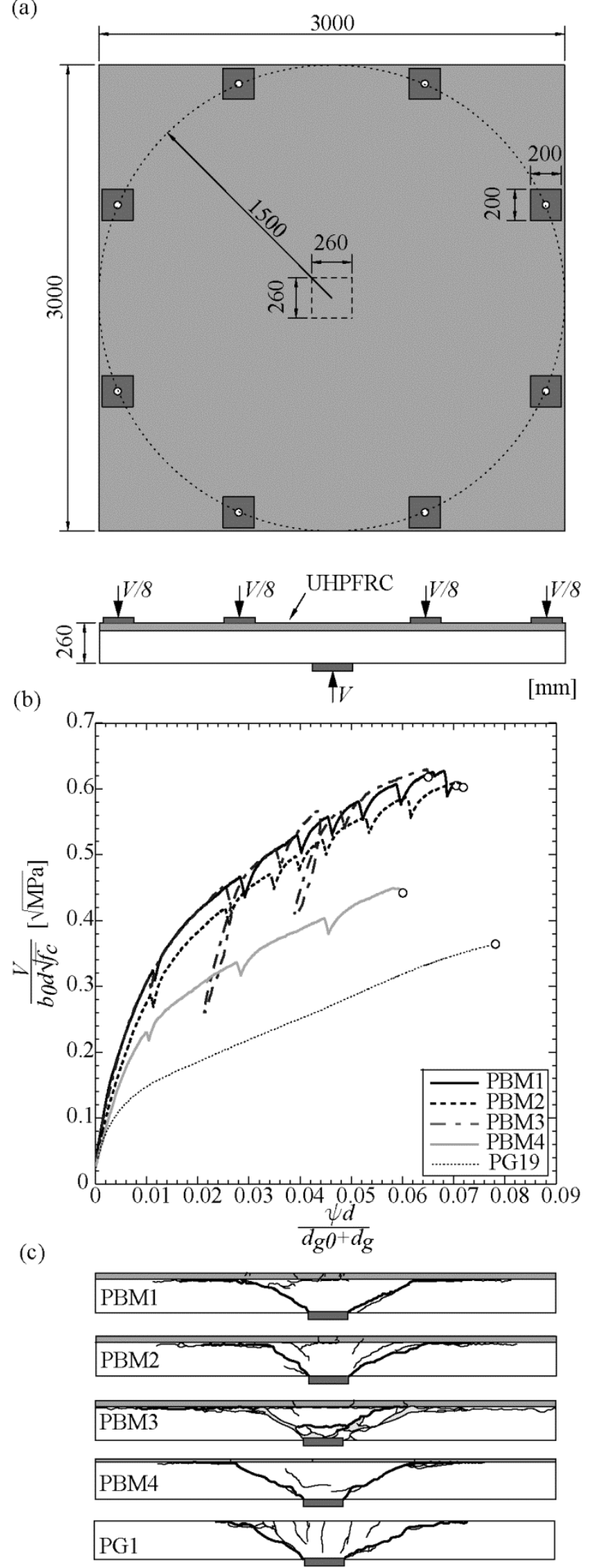

Figure 6. Results of the punching tests: (a) test setup; (b) normalized force-rotation curve; (c) punching cone as observed on the cut slabs after the end of the test

These tests showed that a layer of $50 \mathrm{~mm}$ of UHPFRC (PBM1 to 3 ) increases the resistance of a concrete slab by over $67 \%$ without reducing its rotation capacity. However, the use of reinforcement in the UHPFRC layer brings no added value, as all 
three slabs with the $50 \mathrm{~mm}$ layer, with or without reinforcement, have the same resistance.

The punching cones illustrated in Figure 6c were traced from what was observed on the cut slabs, after the end of the test. In all cases except PBM3, the test was stopped immediately after the punching failure. In the case of PBM3, the test continued after the pic resistance in order to study the post-pic behavior of the slab. As it can be noted, the UHPFRC layer does not significantly modify the angle of the punching cone; the shape of the cone is similar for all 5 slabs.

On Figure 6c, it can also be observed that in all cases, the failure crack rotates just below the interface between the concrete and the UHPFRC layer, at the level of the tensile reinforcement in the concrete. This delamination appears only after the opening of the critical shear crack when the cone tries to push through the layer of UHPFRC. The layer of UHPFRC works in bending as was observed in the case of one-way shear (Fig. 4).

\section{ANALYTICAL MODELS}

Two analytical models are introduced hereafter. They are useful for the correct design of reinforcement with UHPFRC. In all cases, it should be verified that the shear resistance is higher than the bending resistance to insure a ductile flexural failure of the structural element.

\subsection{Behaviour in bending}

As described previously, when a beam reaches ultimate resistance in bending, no debonding between UHPFRC and concrete occurs. The composite beams thus behave monolithically and the hypothesis of Bernoulli - plane sections remain plane- is valid. To calculate the ultimate resisting moment in bending for a composite beam, it was thus proposed to use a plane section analysis as given in Figure 7 (Habel, 2006).

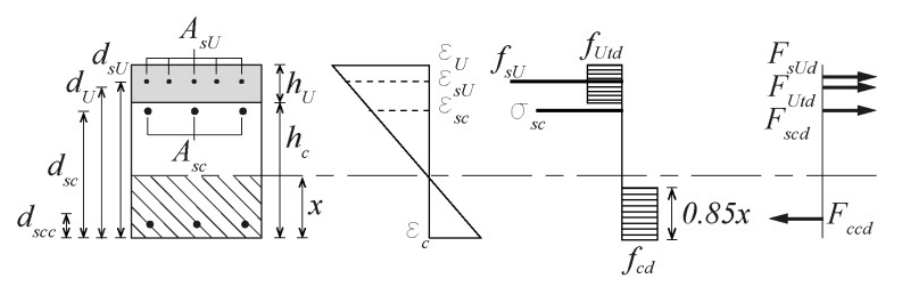

Figure 7. Analytical model for bending (Habel et al., 2006)

To obtain the ultimate resistance, it is supposed that the UHPFRC layer as well as the rebars in the layer and at the top of the concrete section have all yielded. It is then possible to find the height of the neutral axis by stating equilibrium of all the forces on the section.

\subsection{Behaviour in combined bending and shear}

The failure mechanism in combined bending and shear was explained in chapter 3.2 and illustrated in Figure 4.

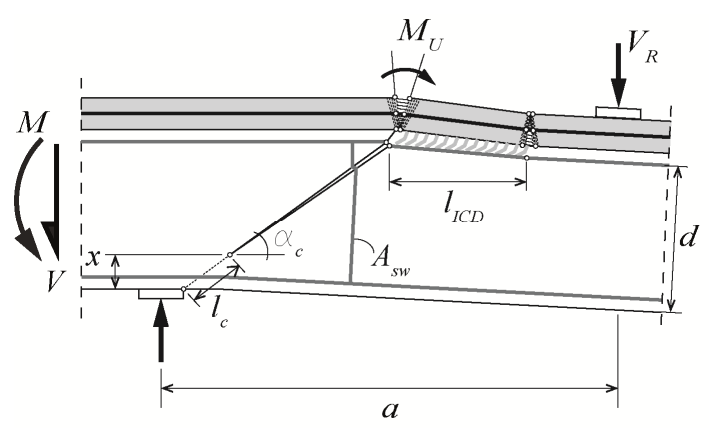

Figure 8. Analytical model for shear (Noshiravani \& Brühwiler, 2013c)

This mechanism is used by Noshiravani \& Brühwiler (2013c) to propose a simplified formulation to evaluate the flexure-shear strength of a composite beam, $V_{R U-R C}$. Equation 2 calculates it as the sum of the contribution of concrete $\left(V_{C}\right)$, stirrups in steel $\left(V_{s}\right)$ and UHPFRC layer $\left(V_{R U}\right)$.

$V_{R U-R C}=V_{C}+V_{S}+V_{R U}$

The shear resistance of concrete $V_{c}$ along the diagonal crack is obtained with Equation 3 proposed by Stoffel (2000). In this equation, $f_{c e}$ is the effective strength of concrete and can be taken as $0,8 f_{c}$. The variable $b$ is the width of the section and can be taken as $1 \mathrm{~m}$ in the case of a slab. The height of the compression zone, $x$, is obtained when the sectional analysis is done for the composite beam (Figs. 7-8). The angle of the diagonal crack with respect to the longitudinal axis angle is $\alpha_{c}$ (Figs 4,8). The value of $\alpha_{c}$ should be between $20^{\circ}$ and $60^{\circ}$.

$V_{c}=\frac{f_{c e} b}{2}\left[\frac{x}{\sin \alpha_{c}}\left(1-\cos \alpha_{c}\right)\right]$

The shear resistance of steel $V_{s}$ is simply the area of shear reinforcement times the yield limit of the steel, as given by Equation 4 .

$V_{s}=A_{s w} f_{s w}$

Finally, the shear resistance of the UHPFRC layer $V_{R U}$ submitted to bending in double curvature is a function of its flexural resistance $M_{R U, \max }$ and the maximum possible length of the ICD zone $l_{I C D, \max }$, as stated by Equations 5. The bending resistance of the layer can be calculated with a plane section analysis while the ICD length is obtained geometrically using the angle of the diagonal crack $\alpha_{c}$ and the span length. The maximum ICD zone develops bellow the interface between the mouth of the diagonal crack and the top support or force point. It is given by Equation 6 where $d_{s c}$ is the static height of the RC section as shown in Figure 7. 
$V_{R U}=\frac{2 M_{R U, \max }}{l_{I C D, \max }}$

$l_{I C D, \max }=a-\frac{d_{S C}}{\tan \alpha_{c}}$

\section{DESIGN EXAMPLE}

In the next section, the design of a composite cantilever slab submitted to concentrated forces is presented. The calculations to evaluate the ultimate resistance are showed step-by-step. The reinforcement of this slab is given in Figure 9. The slab is subjected to two symmetrical concentrated forces applied on an area of $400 \times 400 \mathrm{~mm}$. The proposed material properties are given in Table 1.

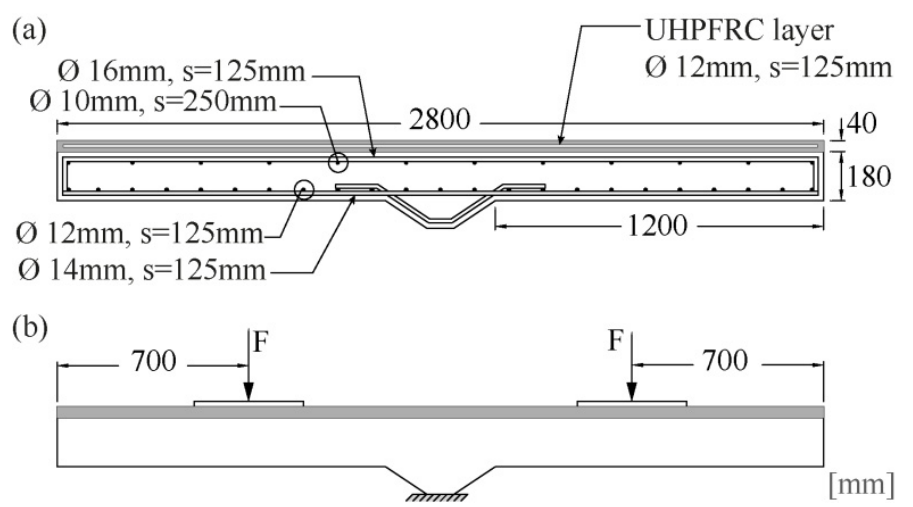

Figure 9. Design example: (a) slab layout and reinforcement; (b) loading pattern.

Table 1. Material properties.

\begin{tabular}{|c|c|c|}
\hline \multicolumn{3}{|l|}{ Concrete } \\
\hline$E_{c}[\mathrm{MPa}]$ & \multicolumn{2}{|c|}{$f_{c}[\mathrm{MPa}]$} \\
\hline 30000 & \multicolumn{2}{|c|}{25} \\
\hline \multicolumn{3}{|l|}{ UHPFRC } \\
\hline$E_{U}[\mathrm{MPa}]$ & $f_{U t}[\mathrm{MPa}$ & $\varepsilon_{U t, u}[\% 0]$ \\
\hline 50000 & 10 & 5 \\
\hline \multicolumn{3}{|l|}{ Steel } \\
\hline$E_{s}[\mathrm{MPa}]$ & $f_{s v}[\mathrm{MPa}]$ & $\varepsilon_{s u}[\% 0]$ \\
\hline 210000 & 550 & 10 \\
\hline
\end{tabular}

\subsection{Bending resistance}

To calculate the ultimate bending resistance, the method proposed in paragraph 4.1 is used. The neutral axis is at $68 \mathrm{~mm}$ from the bottom concrete fiber. It was obtained by iterative calculations. The calculation is summarized in Table 2.

Table 2. Sectional analysis.

\begin{tabular}{l|l|l|l|l|l}
\cline { 2 - 6 } & $\begin{array}{l}\boldsymbol{\varepsilon} \\
{[\%]}\end{array}$ & $\begin{array}{l}\boldsymbol{\sigma} \\
{[\mathbf{M P a}]}\end{array}$ & $\begin{array}{l}\boldsymbol{F} \\
{[\mathbf{k N} / \mathbf{m}]}\end{array}$ & $\begin{array}{l}\text { Static } \\
\text { height } \\
{[\mathbf{m m}]}\end{array}$ & $\begin{array}{l}\text { Moment } \\
{[\mathbf{k N m} / \mathbf{m}]}\end{array}$ \\
\hline UHPFRC & 5 & 10 & 400 & 200 & 80 \\
\hline $\mathrm{A}_{\mathrm{sU}}$ & 4.3 & 550 & 498 & 200 & 100 \\
\hline $\mathrm{A}_{\mathrm{sc}, \mathrm{t}}$ & 2.8 & 550 & 885 & 152 & 135 \\
\hline Concrete & -1.3 & -25 & -1437 & 29 & -41 \\
\hline $\mathrm{A}_{\mathrm{sc}, \mathrm{c}}$ & -1.3 & -280 & -345 & 27 & -9 \\
\hline \multicolumn{7}{r}{} & Total & 265 \\
\cline { 3 - 6 } & & & &
\end{tabular}

The proposed slab was analyzed using the linear elastic theory. This simple method provides a lower bound estimation of the flexural resistance of the slab. It was thus calculated, that the ultimate force $F$ that can be applied to approach the flexural capacity of the slab is $632 \mathrm{kN}$.

\subsection{Shear resistance}

The shear resistance of this slab is calculated for a strip of $1 \mathrm{~m}$ using Equations 2, 3 and 5. This slab has no shear reinforcement, thus $v_{s}$ is equal to zero. The angle of the diagonal crack $\alpha_{c}$ was obtained by iterative calculations in order to get the smallest total shear resistance. The calculations are summarized in Table 3.

Table 3. Shear resistance calculation.

\begin{tabular}{|c|c|}
\hline $\boldsymbol{x}$ & $68 \mathrm{~mm}$ \\
\hline $\boldsymbol{\alpha}_{\boldsymbol{c}}$ & $47^{\circ}$ \\
\hline $\boldsymbol{m}_{\boldsymbol{R}, \text {, } \max }$ & $11 \mathrm{kNm} / \mathrm{m}$ \\
\hline $\boldsymbol{l}_{\boldsymbol{I C D , \text { max }}}$ & $132 \mathrm{~mm}$ \\
\hline $\boldsymbol{v}_{\boldsymbol{c}}$ & $294 \mathrm{kN} / \mathrm{m}$ \\
\hline $\boldsymbol{v}_{\boldsymbol{R} \boldsymbol{U}}$ & $160 \mathrm{kN} / \mathrm{m}$ \\
\hline $\boldsymbol{v}_{\boldsymbol{R} U-\boldsymbol{R} \boldsymbol{C}}$ & $\mathbf{4 5 4} \mathbf{k N} / \mathbf{m}$ \\
\hline
\end{tabular}

The length of the control section was calculated as prescribed by the $f i b$-Model Code 2010 (2012) in the case of a clamped edge support. The load distribution angle to the support is assumed at $45^{\circ}$ and the calculated length is $1500 \mathrm{~mm}$ as illustrated in Figure 10. The ultimate force $F$ that can be applied to get to the shear resistance is thus $681 \mathrm{kN}$.

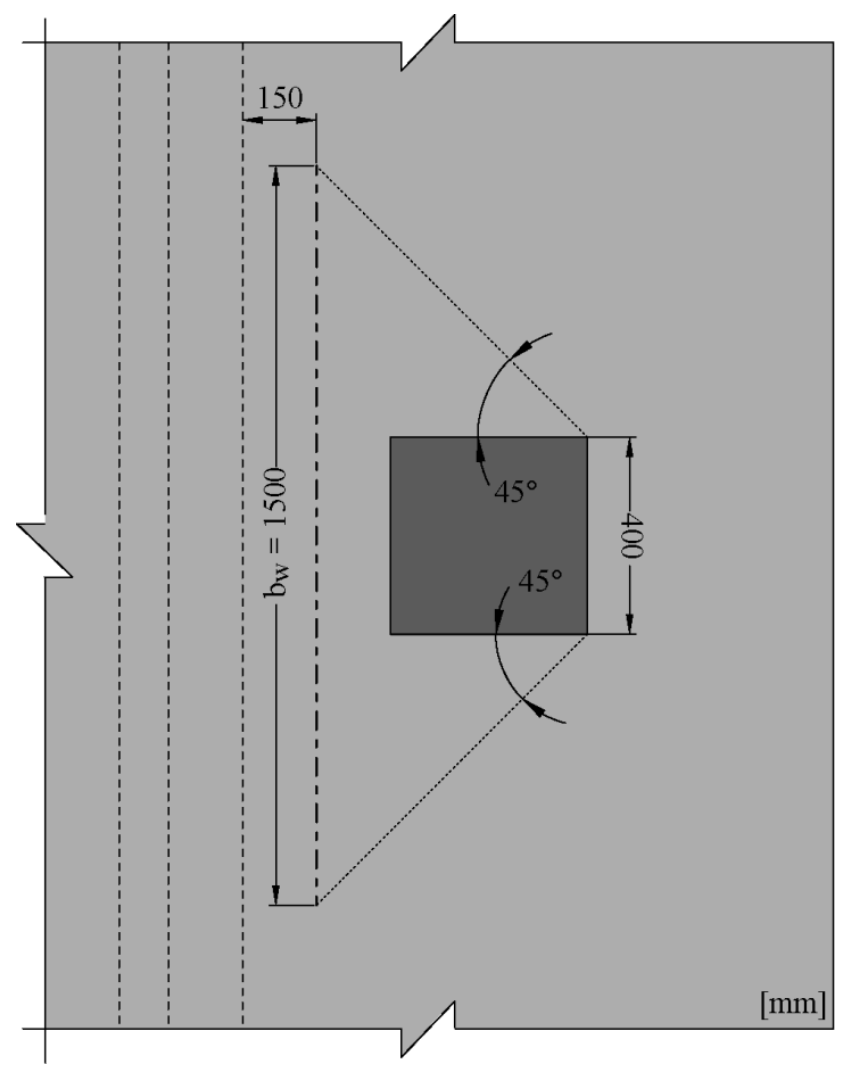

Figure 10. Design example: (a) slab layout and reinforcement; (b) loading pattern. 


\subsection{General comments}

This composite slab has a lower flexural resistance than its shear resistance. Thus the flexural capacity governs the design. A more detailed analysis of the slab using upper bound solutions would be needed in order to get less conservative values.

\section{FIELD APPLICATION}

A RC massive slab bridge supported by 6 columns, built in 1963 and located near Lausanne, in Switzerland, was reinforced with a layer of UHPFRC in autumn 2011 (Fig. 11). Before the intervention, the slab parts over the column supports did not meet the requirements for structural safety in bending and shear of the Swiss standards for existing structures (SIA, 2011).

(a)

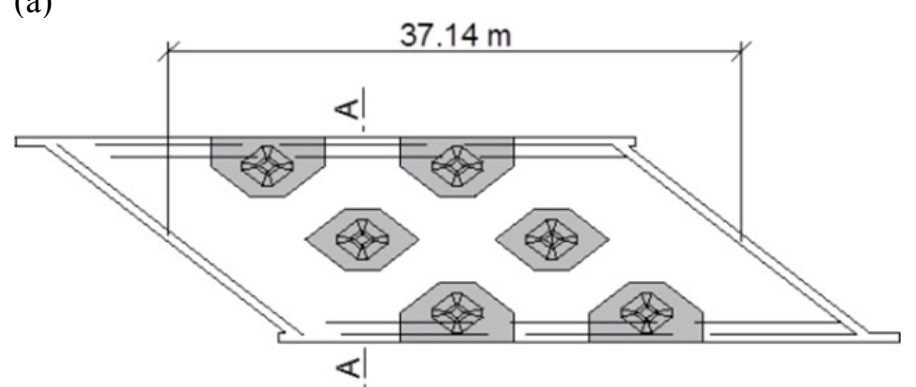

(b)
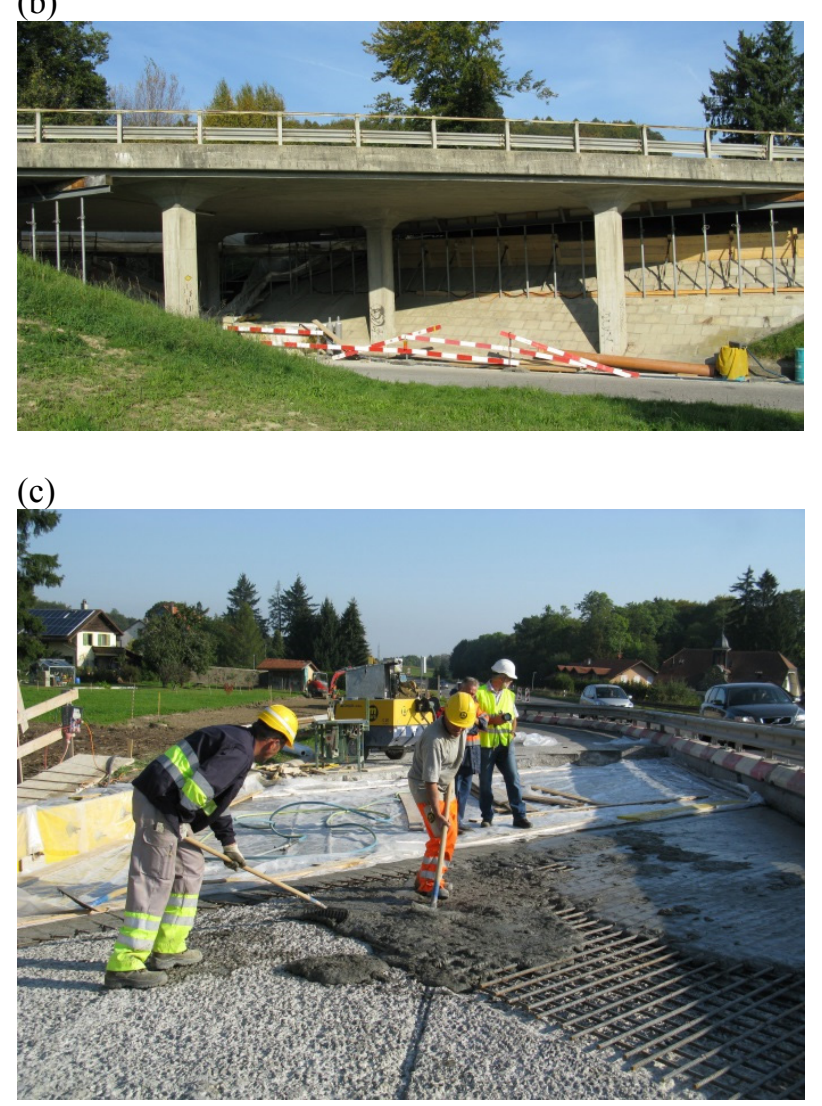

Figure 11. Placing of UHPFRC on bridge slab

The top layer of approximately 20 to $40 \mathrm{~mm}$ of the $\mathrm{RC}$ slab was first removed with high pressure water jet. Then, as proposed before, it was decided to vary the thickness of the layer of UHPFRC across the slab, placing a thicker layer over the columns where more strengthening was needed (Fig. 11c). A layer of $25 \mathrm{~mm}$ of UHPFRC was cast over the slab for strengthening and waterproofing. Over the column supports, a thicker layer of $65 \mathrm{~mm}$ was placed with $18 \mathrm{~mm}$ diameter steel rebars. This intervention significantly improved the load bearing capacity and durability of the bridge. It also demonstrated the simplicity in applying this technology to a full scale structure.

This is only one example out of many strengthening with UHPFRC that has been performed in Switzerland and elsewhere. At the moment of writing this paper, over 20 bridges had been rehabilitated using this technology.

\section{CONCLUSION}

An experimental campaign on composite elements has demonstrated that a layer of R-UHPFRC over a $\mathrm{RC}$ section significantly increases the load bearing capacity. Analytical models are available and their simplicity has been demonstrated by a design example. A site application showed that this concept is also simple to apply to full size structures.

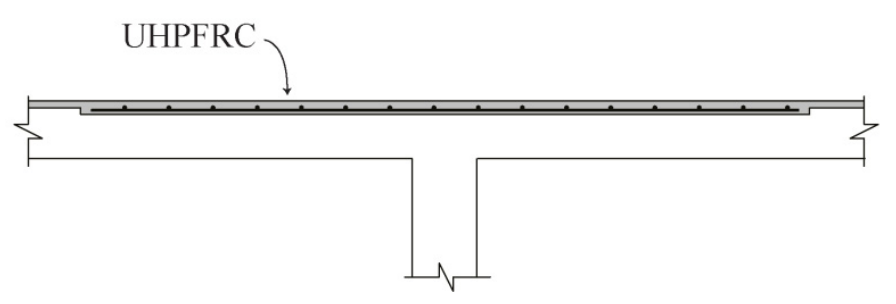

Figure 12. Example of a localized repair on a RC slab

This conceptual idea combines efficiently the protection and resistance properties of UHPFRC. To take advantage of the properties of this material and to optimize its use, it is interesting when designing a reinforcement to identify the zones of the slab that need strengthening and those that simply need waterproofing. The thickness of the layer can therefore vary accordingly adding some extra steel rebars when strengthening is needed as illustrated in Figure 12 . The rehabilitated structures then have a significantly improved structural resistance and durability.

\section{REFERENCES}

Charron J.-P., Dénarié E., \& Brühwiler, E. 2007. Permeability of Ultra-High Performance Fiber Reinforced Concretes (UHPFRC) under high stresses. Materials and Structures 40(3): 269-277.

Bastien-Masse, M. \& Brühwiler, E. 2013. Concrete bridge deck slabs strengthened with UHPFRC. IABSE conference: Assessment, Upgrading and Refurbishment of Infrastructures, Rotterdam, Netherlands, May 2013. 
Brühwiler, E. 2012. Rehabilitation and strengthening of concrete structures using Ultra-High Performance Fiber Reinforced Concrete. Keynote lecture ICCRR:R The International Conference on Concrete Repair, Rehabilitation and Retrofitting, Cape Town, South Africa, September 2012.

Denarié E., \& Brühwiler E. 2011. Strain Hardening of UltraHigh Performance Fibre Reinforced Concrete: Deformability versus Strength Optimization. International Journal for Restoration of Buildings and Monuments, 12(6): 397-410.

Guidotti, R. 2010 Poinçonnement des planchers-dalles avec colonnes superposées fortement sollicitées, Doctoral Thesis, No. 4812, Ecole Polytechnique Fédérale de Lausanne, Lausanne, Suisse.

Habel, K., Denarié, E. \& Brühwiler E. 2006. Structural response of elements combining Ultrahigh-Performance Fiber-Reinforced Concretes (UHPFRC) and reinforced concrete. ASCE Journal of Structural Engineering 132(11): 1793-1800.

Habel K., Denarié E. \& Brühwiler E. 2007. Experimental Investigation of Composite Ultra-High-Performance FiberReinforced Concrete and Conventional Concrete Members ACI Structural Journal 104 (1): 93-101.

International Federation for Structural Concrete (fib). 2012 Model Code 2010 - Final Draft, Lausannw, Switzerland.

Muttoni, A. 2008. Punching Strength of Reinforced Concrete Slabs without Transverse Reinforcement. ACI Structural Journal 105 (4): 440-450.

Noshiravani, T. \& Brühwiler, E. 2013. Experimental Investigation on R-UHPFRC - RC Composite Beams Subjected to Combined Bending and Shear ACI Structural Journal 110 (2) $251-261$.

Noshiravani, T. \& Brühwiler, E. 2013. Rotation Capacity and Stress Redistribution Ability of R-UHPFRC - RC Composite Continuous Beams: An Experimental Investigation. Materials and Structures (Published online February 2013).

Noshiravani, T. \& Brühwiler, E. 2013 Analytical Model for Predicting the Response and Flexure-Shear Resistance of R-UHPFRC - RC Composite Beams. ASCE Journal of Structural Engineering (accepted for publication).

Oesterlee C. 2010. Structural Response of Reinforced UHP$F R C$ and RC Composite Members. Doctoral Thesis, No. 4848, Ecole Polytechnique Fédérale de Lausanne, Switzerland.

Stoffel P. 2000 Zur Beurteilung der Tragsicherheit bestehender Stahlbetonbauten. Doctoral thesis, ETHZ, Zurich, Switzerland.

SIA, SIA 269/2: 2011. Maintenance des structures porteuses Structures en béton, Swiss society of engineers and architects, Zurich. 